\title{
Integrated fever management: disease severity markers to triage children with malaria and non-malarial febrile illness
}

\author{
Chloe R. McDonald ${ }^{1}$, Andrea Weckman², Melissa Richard-Greenblatt ${ }^{1}$, Aleksandra Leligdowicz ${ }^{1,3}$ \\ and Kevin C. Kain ${ }^{1,2,4,5^{*}}$ (D)
}

\begin{abstract}
Febrile symptoms in children are a leading cause of health-care seeking behaviour worldwide. The majority of febrile illnesses are uncomplicated and self-limited, without the need for referral or hospital admission. However, current diagnostic tools are unable to identify which febrile children have self-limited infection and which children are at risk of progressing to life-threatening infections, such as severe malaria. This paper describes the need for a simple community-based tool that can improve the early recognition and triage of febrile children, with either malarial or non-malarial illness, at risk of critical illness. The integration of a disease severity marker into existing malaria rapid diagnostic tests (RDT) could enable detection of children at risk of severe infection in the hospital and community, irrespective of aetiology. Incorporation of a disease severity marker could inform individualized management and early triage of children at risk of life-threatening infection. A child positive for both malaria and a disease severity marker could be prioritized for urgent referral/admission and parenteral therapy. A child positive for malaria and negative for a disease severity marker could be managed conservatively, as an out-patient, with oral anti-malarial therapy. An RDT with a disease severity marker could facilitate an integrated community-based approach to fever syndromes and improve early recognition, risk stratification, and prompt treatment of severe malaria and other life-threatening infections.
\end{abstract}

Keywords: Malaria, Disease severity, Severe malaria, Innate immunity, Inflammation, Endothelial activation

\section{Background}

\section{Statement of problem}

Febrile syndromes account for over 1 billion episodes annually and are one of the most common reasons to seek medical care worldwide [1, 2]. A child in sub-Saharan Africa will experience a mean of 5.9 episodes of fever each year, translating into more than 660 million episodes annually across the sub-continent $[2,3]$. The majority of these febrile illnesses are uncomplicated and self-limited, and only a small proportion of children progress to serious infections including severe malaria. However, there

\footnotetext{
*Correspondence: kevin.kain@uhn.ca

1 SAR Laboratories, Sandra Rotman Centre for Global Health, University Health Network-Toronto General Hospital, MaRS Centre, TMDT, 10th Floor 10-351, Toronto, ON M5G 1L7, Canada

Full list of author information is available at the end of the article
}

is a lack of rapid and reliable tools to identify which children have, or are progressing to, life-threatening infections. This is a major barrier to rational triage and management of fever syndromes and results in increased mortality in those with severe infections and the misallocation of scarce health resources due to inappropriate referral, admission and/or antimicrobial treatment of patients with self-limited infections, resulting in harm, increased health care costs and antimicrobial resistance.

\section{Proposed solution}

This paper advocates for the development of rapid and simple tools to enhance the early recognition and triage of severe malaria and other life-threatening infections in the community setting. This approach would permit integrated community-based management of "all cause" fever 
(See figure on next page.)

Fig. 1 Overview of the global burden of malaria in children under five. There were an estimated 216 million cases of malaria infection in 2016. The majority of malaria cases and fatalities occur in sub-Saharan Africa. An estimated $\leq 1 \%$ of all malaria infections present with or progress to severe disease, which is associated with an increased risk of morbidity and mortality. Current barriers to improved management and outcome for paediatric febrile illnesses include the lack of simple and rapid tools to enhance triage and referral of severe malaria and other life-threatening infections [7], Licence: CC BY-NC-SA 3.0 IGO

syndromes. By avoiding unnecessary referral of self-limited and uncomplicated infections, it would decompress health care facilities, while focusing health resources on those at risk of severe infection that are most likely to benefit from referral, admission and supportive care. This strategy could save lives and health dollars.

\section{Severity markers to triage fever syndromes Severe malaria as a model-challenges and opportunities}

Malaria remains a major contributor to childhood death and disability [4]. In 2016 there were over 216 million reported cases of malaria infection resulting in 290,000 deaths in children under the age of five (Fig. 1). Up to one quarter of all children who survive severe malaria experience long-term neurological sequelae including impaired learning, epilepsy, and increased risk of behavioural disorders [4-6].

As a result of current malaria control and elimination efforts, malaria prevalence is changing and the proportion of fevers due to malaria is decreasing in many regions of Africa (ranging from $\leq 10$ to $>70 \%$ [7]). The roll out of malaria rapid diagnostic tests (RDT) has enhanced the management of uncomplicated malaria, but has also created new challenges; in particular how best to manage the large number of children with non-malarial fevers. This barrier has resulted in an escalation of inappropriate antibiotic use. For example, in an analysis of observational and randomized studies that included over 500,000 febrile participants, antibiotics were prescribed to $69 \%$ of patients who were RDT negative, with lower anti-malarial use being replaced with increased antibiotic use $[8,9]$.

An integrated approach is required to provide rational management of both malaria positive and malaria-negative cases and enhance the early recognition and triage of severe infections.

\section{Current malaria RDTs cannot diagnose severe disease}

The early recognition and treatment of children with severe malaria can improve survival but, like sepsis, the initial presentation may be subtle and non-specific [2, 10-13]. Malaria diagnosis across many hospital and community-based settings relies on RDTs that detect circulating parasite antigens. While pathogen-based tests have transformed diagnosis, they do not advise management beyond the presence or absence of infection. Specifically they do not inform critical management decisions regarding patients who have, or are progressing to severe disease, and consequently need urgent referral/admission and parenteral therapy. In an era of "patient first medicine", a sole focus on the pathogen is not a small problem. For example, in a large survey of severe malaria management in 103 health units in Uganda, referral practices to formal health care centers were reported to be appropriate in less than $10 \%$ of cases, while less than $30 \%$ of those with severe malaria were diagnosed and treated promptly [14]. Similar problems may exist elsewhere in malariaendemic areas $[12,15,16]$. As with other life-threatening infections, delays in the recognition and treatment of severe malaria result in increased mortality and long-term morbidity in survivors [10, 11, 17], whereas over-referral and admission of uncomplicated cases misallocates limited health resources and causes harm [10, 14].

\section{Endothelial and immune activation markers can identify patients with severe malaria}

Clinical evaluation of infection-related disease severity remains imprecise in paediatric and adult populations in both low and high resource settings, indicating a need for more accurate tools $[13,14]$. The outcome of any infection depends on a complex interplay between the pathogen and host. Host response is a critical determinant of the onset and outcome of severe infections and several lines of evidence indicate that lifethreatening infections share common pathways of host response leading to end-organ injury [18-29]. Of these shared pathways, endothelial and immune activation have emerged as key contributors to the pathogenesis of severe and fatal infections [24-30]. Endothelial and immune activation precedes the loss of endothelial integrity, microvascular leak, multi-organ dysfunction and death $[28,30-32]$. Markers of these pathways (e.g. Angiopoietin/Tie2) have been shown to be independent and quantitative markers of disease severity and prognosis, not only in in Plasmodium falciparum malaria, but also in Plasmodium vivax and Plasmodium knowlesi, as well as sepsis and other infections [21, 22, 26, 30-39]. Moreover, unlike C-reactive protein (CRP) and procalcitonin (PCT), these markers are actual pathway mediators and therefore represent "druggable" targets to improve the outcome of lifethreatening infections [30, 40,41]. Collectively, these 


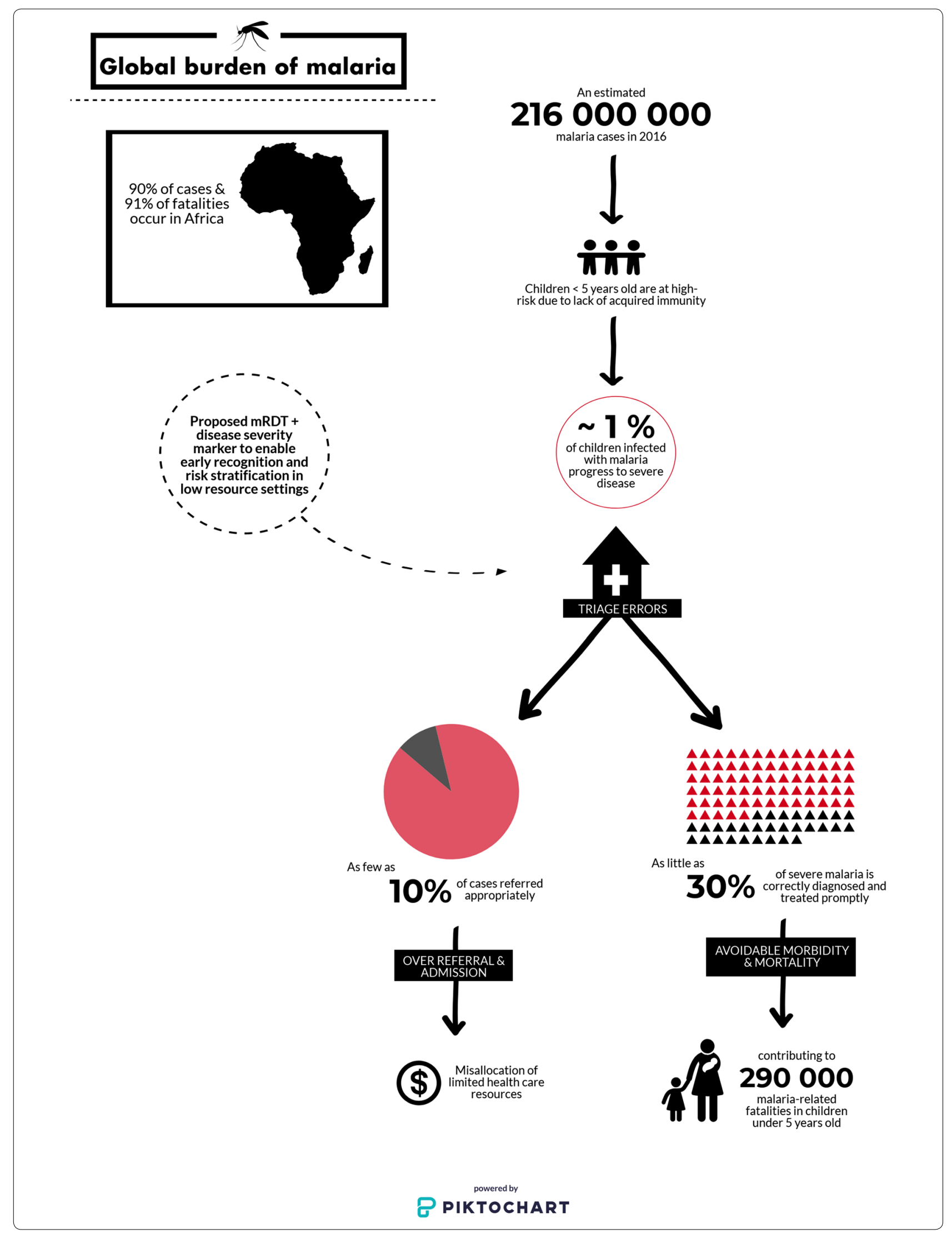




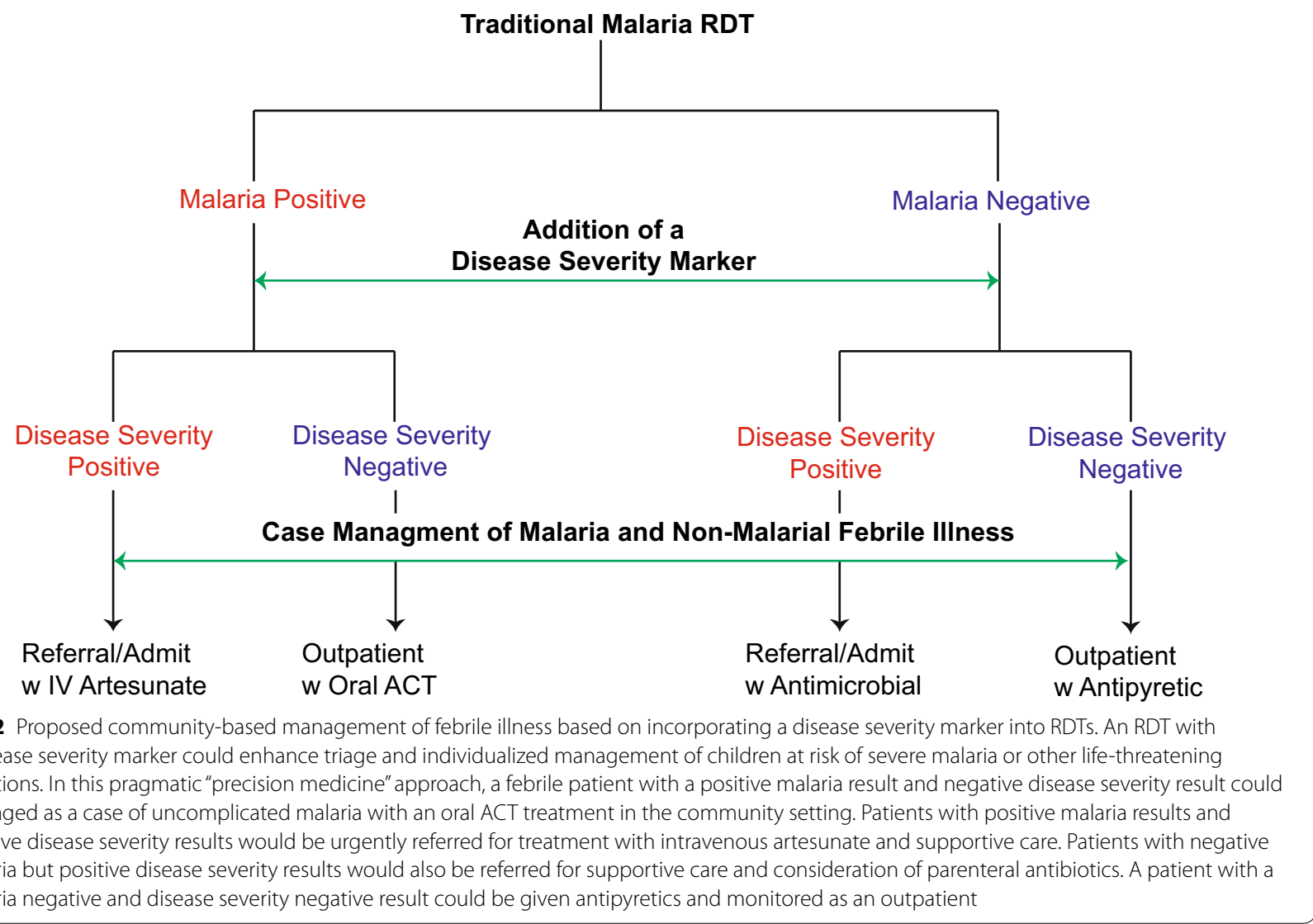

data support the hypothesis that measuring these markers at clinical presentation could facilitate triage, risk-stratification and precision management of malaria-infected patients.

\section{Integrating severity markers into existing RDTs to identify cases of severe malaria}

RDTs are already widely implemented in communitybased settings in Asia and Africa. These culturally acceptable and inexpensive diagnostic platforms could be adapted to incorporate a disease severity marker, enabling not only the detection of malaria, but simultaneously informing individualized management decisions regarding the need for referral and parenteral therapy (Fig. 2). In this proposed community-based approach, a febrile patient with a positive malaria result and negative disease severity result could be managed as uncomplicated malaria in the community with oral artemisinin-based combination therapy (ACT), whereas a patient with a positive malaria result and positive disease severity marker warrants urgent referral and parenteral artesunate.
Using markers of severity to risk-stratify non-malarial febrile illness

Depending on the location and season, up to $90 \%$ of RDTs used in the community setting in sub-Saharan Africa will be negative $[8,9,14]$. An integrated approach is needed to manage febrile illness and triage children at risk of life-threatening infection irrespective of aetiology. While additional prospective studies are needed, the triage approach described above for malaria, could also inform precision management for RDT-negative cases.

Most patients with non-malarial febrile illness have self-limiting infections [42]. Patients with impending severe infections require immediate referral for more advanced care and consideration for parenteral antimicrobial therapy $[10,43]$. Enhanced pathogen-based diagnostics can potentially inform management with respect to antimicrobial therapy, but as in severe malaria, do not inform decisions as to which patients would most benefit from referral and hospital-based care.

For non-malarial fever, detailed studies have examined the utility of etiological data to guide triage and treatment [42]. However, acting on these data can be problematic due to the frequency of mixed infections-making 
assignment of causality challenging-further confounded by the high rate of carriage of pathogenic organisms in healthy controls. Rather than multiple pathogen-based approaches and the challenges posed by their logistics and interpretation by community health-workers, rapid tests for severe infections could have direct impact since in the absence of critical illness, most non-malarial febrile syndromes can be managed conservatively and without antimicrobials [43-46].

As above, markers of endothelial and immune activation (e.g. Angiopoietin/Tie2 axis, soluble triggering receptor expressed on myeloid cells-1 (sTREM-1)) predict clinical outcome in patients with non-malarial febrile illness, and could be used to risk-stratify patients and inform clinical management irrespective of aetiology [22, $26,39,47]$. However additional studies are needed to further define their clinical utility, especially in low-resource community settings.

\section{Enabling triage of severe infections in community-based settings}

Many deaths in children under five in low resource settings occur in remote regions. Rural place of residence is associated with an increased risk of delayed access to medical treatment and death before the age of five [48]. More than $50 \%$ of children in low resource settings die in the community without ever engaging the formal health care system [3, 48, 49]. Therefore, reducing under-five mortality will require triage tools that can be deployed in rural communities. This requires tools that are suitable for use by frontline community health workers and that empower them to make important management decisions at initial patient presentation. A "next generation" triage tool that incorporates a disease severity marker into existing RDTs would be appropriate for communitybased triage and could improve case management of both malaria and non-malarial fever syndromes. Enhanced triage in the community could enable early detection of severe infections, facilitate timely referral and lead to improved health outcomes.

\section{Conclusions}

The majority of febrile illness in children under the age of five is self-limited and, once malaria and critical illness are excluded, can be managed conservatively. The current inability to rapidly identify the small proportion of children who are at risk of progressing to life-threatening infection is a major obstacle to management of fever syndromes, rational antimicrobial use and effective health resource allocation. This paper proposes the incorporation of disease severity markers into existing RDTs as an approach to enable early recognition, risk stratification, and prompt treatment of severe malaria and other life-threatening infections. While additional studies are needed, this strategy could enhance triage, improve case management, resource allocation, and ultimately health outcomes for children presenting with both malarial and non-malarial febrile illness in hospital and communitybased settings.

\section{Abbreviations \\ ACT: artemisinin-based combination therapy; CRP: C-reactive protein; RDT: rapid diagnostic test; $\mathrm{PCT}$ : procalcitonin; sTREM1: soluble triggering receptor expressed on myeloid cells-1.}

\section{Authors' contributions}

The manuscript was prepared with input from CRM, AW, JW, MRG and KCK. All authors read and approved the final manuscript.

\section{Author details}

${ }^{1}$ SAR Laboratories, Sandra Rotman Centre for Global Health, University Health Network-Toronto General Hospital, MaRS Centre, TMDT, 10th Floor 10-351, Toronto, ON M5G 1L7, Canada. ${ }^{2}$ Department of Laboratory Medicine and Pathobiology, University of Toronto, Toronto, Canada. ${ }^{3}$ Interdepartmental Division of Critical Care Medicine, University of Toronto, Toronto, Canada. ${ }^{4}$ Tropical Disease Unit, Division of Infectious Diseases, Department of Medicine, University of Toronto, Toronto, Canada. ${ }^{5}$ Toronto General Research Institute, Toronto General Hospital, Toronto, Canada.

\section{Acknowledgements \\ Not applicable.}

\section{Competing interests}

KCK is a named inventor on a patent "Biomarkers for early determination of a critical or life-threatening response to illness and/or treatment response" held by the University Health Network. Remaining authors declare that they have no competing interests.

\section{Availability of data and materials \\ Not applicable.}

\section{Consent for publication}

Not applicable.

Ethics approval and consent to participate

Not applicable.

\section{Funding}

This work was supported by the Canadian Institutes of Health Research (CIHR) Foundation Grant FDN-148139 and Canada Research Chair [KCK]. AW is supported by a CIHR Graduate Studentship.

\section{Publisher's Note}

Springer Nature remains neutral with regard to jurisdictional claims in published maps and institutional affiliations.

Received: 22 August 2018 Accepted: 19 September 2018 Published online: 10 October 2018

References

1. de Bont EG, Lepot JM, Hendrix DA, Loonen N, Guldemond-Hecker Y, Dinant GJ, et al. Workload and management of childhood fever at general practice out-of-hours care: an observational cohort study. BMJ Open. 2015;5:e007365.

2. WHO. Informal consultation on fever management in peripheral health care settings: a global review of evicence and practice. Geneva: World Health Organization; 2013. 
3. Hay SI, Guerra CA, Tatem AJ, Noor AM, Snow RW. The global distribution and population at risk of malaria: past, present, and future. Lancet Infect Dis. 2004:4:327-36

4. Christensen SS, Eslick GD. Cerebral malaria as a risk factor for the development of epilepsy and other long-term neurological conditions: a meta-analysis. Trans R Soc Trop Med Hyg. 2015;109:233-8.

5. Bangirana P, Menk J, John CC, Boivin MJ, Hodges JS. The association between cognition and academic performance in Ugandan children surviving malaria with neurological involvement. PLoS One. 2013;8:e55653.

6. Idro R, Marsh K, John CC, Newton CR. Cerebral malaria: mechanisms of brain injury and strategies for improved neurocognitive outcome. Pediatr Res. 2010;68:267-74.

7. WHO. World malaria report 2017. Geneva: World Health Organization; 2017.

8. Hopkins H, Bruxvoort KJ, Cairns ME, Chandler Cl, Leurent B, Ansah EK, et al. Impact of introduction of rapid diagnostic tests for malaria on antibiotic prescribing: analysis of observational and randomised studies in public and private healthcare settings. BMJ. 2017;356:j1054.

9. Bruxvoort KJ, Leurent B, Chandler CIR, Ansah EK, Baiden F, Bjorkman A, et al. The impact of introducing malaria rapid diagnostic tests on fever case management: a synthesis of ten studies from the ACT Consortium. Am J Trop Med Hyg. 2017;97:1170-9.

10. Nolan T, Angos P, Cunha AJ, Muhe L, Qazi S, Simoes EA, et al. Quality of hospital care for seriously ill children in less-developed countries. Lancet. 2001;357:106-10.

11. Molyneux E, Ahmad S, Robertson A. Improved triage and emergency care for children reduces inpatient mortality in a resource-constrained setting. Bull World Health Organ. 2006;84:314-9.

12. Makumbe B, Tshuma C, Shambira G, Mungati M, Gombe NT, Bangure $D$, et al. Evaluation of severe malaria case management in Mazowe District, Zimbabwe, 2014. Pan Afr Med J. 2017;27:33.

13. Fernando SM, Rochwerg B, Reardon PM, Thavorn K, Seely AJE, Perry $J$ J, et al. Emergency Department disposition decisions and associated mortality and costs in ICU patients with suspected infection. Crit Care. 2018;22:172

14. Achan J, Tibenderana J, Kyabayinze D, Mawejje H, Mugizi R, Mpeka B, et al. Case management of severe malaria-a forgotten practice: experiences from health facilities in Uganda. PLoS One. 2011;6:e17053.

15. Zurovac D, Machini B, Kiptui R, Memusi D, Amboko B, Kigen S, et al. Monitoring health systems readiness and inpatient malaria case-management at Kenyan county hospitals. Malar J. 2018;17:213.

16. Namuyinga RJ, Mwandama D, Moyo D, Gumbo A, Troell P, Kobayashi $M$, et al. Health worker adherence to malaria treatment guidelines at outpatient health facilities in southern Malawi following implementation of universal access to diagnostic testing. Malar J. 2017;16:40.

17. Conroy AL, Hawkes M, Elphinstone RE, Morgan C, Hermann L, Barker $\mathrm{KR}$, et al. Acute kidney injury is common in pediatric severe malaria and is associated with increased mortality. Open Forum Infect Dis. 2016;3:ofw046.

18. Ricciuto DR, dos Santos CC, Hawkes M, Toltl LJ, Conroy AL, Rajwans $\mathrm{N}$, et al. Angiopoietin-1 and angiopoietin-2 as clinically informative prognostic biomarkers of morbidity and mortality in severe sepsis. Crit Care Med. 2011;39:702-10.

19. Valim C, Ahmad R, Lanaspa M, Tan Y, Acacio S, Gillette MA, et al. Responses to bacteria, virus, and malaria distinguish the etiology of pediatric clinical pneumonia. Am J Respir Crit Care Med. 2016;193:448-59.

20. Erdman LK, Petes C, Lu Z, Dhabangi A, Musoke C, Cserti-Gazdewich CM, et al. Chitinase 3-like 1 is induced by Plasmodium falciparum malaria and predicts outcome of cerebral malaria and severe malarial anaemia in a case-control study of African children. Malar J. 2014;13:279.

21. Erdman LK, Dhabangi A, Musoke C, Conroy AL, Hawkes M, Higgins S, et al. Combinations of host biomarkers predict mortality among Ugandan children with severe malaria: a retrospective case-control study. PLoS One. 2011;6:e17440.

22. Mikacenic C, Hahn WO, Price BL, Harju-Baker S, Katz R, Kain KC, et al. Biomarkers of endothelial activation are associated with poor outcome in critical illness. PLoS One. 2015;10:e0141251.

23. Poukoulidou T, Spyridaki A, Mihailidou I, Kopterides P, Pistiki A, Alexiou Z, et al. TREM-1 expression on neutrophils and monocytes of septic patients: relation to the underlying infection and the implicated pathogen. BMC Infect Dis. 2011;11:309.

24. Xing K, Murthy S, Liles WC, Singh JM. Clinical utility of biomarkers of endothelial activation in sepsis-a systematic review. Crit Care. 2012;16:R7.

25. Page AV, Liles WC. Biomarkers of endothelial activation/dysfunction in infectious diseases. Virulence. 2013;4:507-16.

26. Leligdowicz A, Richard-Greenblatt M, Wright J, Crowley VM, Kain KC. Endothelial activation: the Ang/Tie axis in sepsis. Front Immunol. 2018;9:838.

27. Kim H, Higgins S, Liles WC, Kain KC. Endothelial activation and dysregulation in malaria: a potential target for novel therapeutics. Curr Opin Hematol. 2011;18:177-85.

28. Ghosh CC, David S, Zhang R, Berghelli A, Milam K, Higgins SJ, et al. Gene control of tyrosine kinase TIE2 and vascular manifestations of infections. Proc Natl Acad Sci USA. 2016;113:2472-7.

29. Page AV, Kotb M, McGeer A, Low DE, Kain KC, Liles WC. Systemic dysregulation of angiopoietin-1/2 in streptococcal toxic shock syndrome. Clin Infect Dis. 2011;52:e157-61.

30. Higgins SJ, Purcell LA, Silver KL, Tran V, Crowley V, Hawkes M, et al. Dysregulation of angiopoietin-1 plays a mechanistic role in the pathogenesis of cerebral malaria. Sci Transl Med. 2016;8:358ra128.

31. David S, Mukherjee A, Ghosh CC, Yano M, Khankin EV, Wenger JB, et al. Angiopoietin-2 may contribute to multiple organ dysfunction and death in sepsis. Crit Care Med. 2012;40:3034-41.

32. Hendrickson CM, Matthay MA. Endothelial biomarkers in human sepsis: pathogenesis and prognosis for ARDS. Pulm Circ. 2018;8:2045894018769876.

33. Lee WL, Liles WC. Endothelial activation, dysfunction and permeability during severe infections. Curr Opin Hematol. 2011;18:191-6.

34. Lovegrove FE, Tangpukdee N, Opoka RO, Lafferty El, Rajwans N, Hawkes $M$, et al. Serum angiopoietin-1 and -2 levels discriminate cerebral malaria from uncomplicated malaria and predict clinical outcome in African children. PLoS One. 2009;4:e4912

35. Yeo TW, Lampah DA, Gitawati R, Tjitra E, Kenangalem E, Piera K, et al. Angiopoietin-2 is associated with decreased endothelial nitric oxide and poor clinical outcome in severe falciparum malaria. Proc Natl Acad Sci USA. 2008;105:17097-102.

36. Barber BE, William T, Grigg MJ, Parameswaran U, Piera KA, Price RN, et al. Parasite biomass-related inflammation, endothelial activation, microvascular dysfunction and disease severity in vivax malaria. PLoS Pathog. 2015;11:e1004558.

37. Barber BE, Grigg MJ, William T, Piera KA, Boyle MJ, Yeo TW, et al. Effects of aging on parasite biomass, inflammation, endothelial activation, microvascular dysfunction and disease severity in Plasmodium knowlesi and Plasmodium falciparum malaria. J Infect Dis. 2017:215:1908-17.

38. Conroy AL, Phiri H, Hawkes M, Glover S, Mallewa M, Seydel KB, et al. Endothelium-based biomarkers are associated with cerebral malaria in Malawian children: a retrospective case-control study. PLoS One. 2010;5:e15291

39. Hahn WO, Mikacenic C, Price BL, Harju-Baker S, Katz R, Himmelfarb $J$, et al. Host derived biomarkers of inflammation, apoptosis, and endothelial activation are associated with clinical outcomes in patients with bacteremia and sepsis regardless of microbial etiology. Virulence. 2016:7:387-94

40. Han S, Lee SJ, Kim KE, Lee HS, Oh N, Park I, et al. Amelioration of sepsis by TIE2 activation-induced vascular protection. Sci Transl Med. 2016:8:335ra355.

41. Saharinen $P$, Eklund $L$, Alitalo K. Therapeutic targeting of the angiopoietin-TIE pathway. Nat Rev Drug Discov. 2017;16:635-61.

42. D'Acremont V, Kilowoko M, Kyungu E, Philipina S, Sangu W, KahamaMaro J, et al. Beyond malaria-causes of fever in outpatient Tanzanian children. N Engl J Med. 2014;370:809-17.

43. George EC, Walker AS, Kiguli S, Olupot-Olupot P, Opoka RO, Engoru C, et al. Predicting mortality in sick African children: the FEAST Paediatric Emergency Triage (PET) score. BMC Med. 2015;13:174.

44. Molyneux EM, Graham SM. Community management of severe pneumonia in children. Lancet. 2011;378:1762-4.

45. Maitland K. New diagnostics for common childhood infections. N Engl J Med. 2014;370:875-7. 
46. Keitel K, Kagoro F, Samaka J, Masimba J, Said Z, Temba H, et al. A novel electronic algorithm using host biomarker point-of-care tests for the management of febrile illnesses in Tanzanian children (e-POCT): a randomized, controlled non-inferiority trial. PLoS Med. 2017;14:e1002411.

47. Higgins SJ, De Ceunynck K, Kellum JA, Chen X, Gu X, Chaudhry SA, et al. Tie2 protects the vasculature against thrombus formation in systemic inflammation. J Clin Invest. 2018;128:1471-84.
48. Rutherford ME, Dockerty JD, Jasseh M, Howie SR, Herbison P, Jeffries $D J$, et al. Access to health care and mortality of children under 5 years of age in the Gambia: a case-control study. Bull World Health Organ. 2009;87:216-24.

49. Battle KE, Bisanzio D, Gibson HS, Bhatt S, Cameron E, Weiss DJ, et al. Treatment-seeking rates in malaria endemic countries. Malar J. 2016;15:20.
Ready to submit your research? Choose BMC and benefit from:

- fast, convenient online submission

- thorough peer review by experienced researchers in your field

- rapid publication on acceptance

- support for research data, including large and complex data types

- gold Open Access which fosters wider collaboration and increased citations

- maximum visibility for your research: over $100 \mathrm{M}$ website views per year

At BMC, research is always in progress.

Learn more biomedcentral.com/submissions 